\title{
Um olhar sobre o processo criativo de empresas de streaminge a experimentação em produçōes audiovisuais
}

\author{
Karina Bousso ${ }^{1}$ \\ Cecilia Almeida Salles ${ }^{2}$
}

Introdução

A PROPOSTA DO PRESENTE ARTIGO É APRESENTAR UMA REFLEXÃO SOBRE AS PRODUÇÕES AUDIOVISUAIS E A MANEIRA EM QUE ESTES CONTEÚDOS SÃO CRIADOS NO ÂMBITO DA ERA DIGITAL E DO STREAMING. Como serviçO de streaming, definimos qualquer tecnologia que através da transferência de dados, principalmente com a utilização da internet, permite o acesso a conteúdos e informações de multimídia. Uma das grandes e maiores referências de conteúdo é a empresa Netflix. Lançada em 1997 por Reed Hastings e Marc Randolph como uma locadora em ambiente on-line, hoje, é conhecida como um dos maiores serviços de streaming para assistir a séries e filmes.

Além da transmissão de produções diversas, desde 2013, a empresa também é conhecida por produzir conteúdos originais como forma de instigar o consumidor a manter-se conectado com a plataforma. Uma das principais referências deste conteúdo e conhecida como a primeira série original é House of Cards que, em 2018, lançou sua $6^{a}$ e última temporada. Outras séries importantes a serem mencionadas aqui são: Orange is the New Black, Narcos e 13 Reasons Why. Esta, lançada em março de 2017, recebeu muita atenção do público por se tratar de temas como depressão, estupro e suicídio entre jovens.

Percebemos a importância e o efeito que a empresa possui hoje no mercado de entretenimento. No entanto, não se pode ignorar as concorrências que permeiam o mesmo serviço de streaming e que, assim como a Netflix, estão permitindo mais acesso a conteúdos de forma mais rápida. É importante mencionar os principais concorrentes: HBO Go, Amazon Prime Video, Apple Tv+ e Disney+. Destacamos assim, a importância do serviço de streaming e a maneira em que estas plataformas são um exemplo de como o indivíduo se tornou cada vez mais seleto no conteúdo que consome e, consequentemente, mais exigente de conteúdos originais.

Inicialmente, o computador ofereceu amplas oportunidades de interação com o conteúdo das mídias e, enquanto operou nesse nível, foi relativamente fácil para as empresas de mídia controlar o que ocorria. Cada vez mais, entretanto, a web tem se tornado um local de participação do consumidor, que inclui muitas maneiras não autorizadas e não previstas de relação com o conteúdo de mídia. ${ }^{3}$

Sem dúvida, o que o streaming permitiu, foi a distribuição de conteúdo para pequenos nichos que buscarão o mesmo tipo de série em qualquer lugar e em qualquer momento. Desta forma, cabe-se aqui, realizar uma reflexão a fim de estabelecer de que maneira a busca pela maior quantidade de conteúdo, atrapalha ou beneficia a busca pela melhor qualidade nas produções.

\footnotetext{
1 Doutoranda em Comunicação e Semiótica pela Pontifícia Universidade Católica de São Paulo (PUC-SP). E-mail: kbousso@gmail.com.

${ }^{2}$ Professora titular do Programa de Pós-Graduação em Comunicação e Semiótica da Pontifícia Universidade Católica de São Paulo (PUC-SP). E-mail: cecilia.salles@gmail.com.

${ }^{3}$ JENKINS, Henry. Cultura da convergência. Tradução de Susana L. de Alexandria. 2a ed., São Paulo: Aleph, 2009 , p. 190.
} 
Ao levar em consideração a empresa Netflix como um principal exemplo do fenômeno de streaming, principalmente pelo pioneirismo, é preciso então considerar esta empresa como foco para seguir com quaisquer argumentações sobre a reflexão proposta. Assim, seguiremos para expor três pontos principais que podem ser reconhecidos no processo criativo no conteúdo desta plataforma específica, dos quais chamaremos de "nós da rede" conforme apontado por Pierre Musso e Cecília Salles. Os três pontos são: Produção de Conteúdo, Algoritmo Monitorado e Reprodução Instantânea.

$\mathrm{O}$ autor Pierre Musso define a rede a partir do olhar sob um corpo estruturado. Conforme aponta o autor, o corpo é definido "como um conjunto de redes compostas de canais ou vasos, isto é, um emaranhado de vínculos que se 'entrecruzam'. O organismo se define por continentes ou 'capacidades' cuja forma é determinada, e pela circulação de um conceito fluido". É possível classificar a definição do autor sobre uma maneira de olhar para qualquer estrutura que permite ligações e convergências a fim de chegar a um objetivo final.

Para falar sobre a rede composta no processo criativo, citamos Cecilia Salles, para salientar a importância de como estes "nós da rede" representam um processo que não é visto como linear pois ele em si se estabelece como particularidades que promovem interações definidas por diferentes critérios. Conforme aponta a autora:

Incorporo, desse modo, também o conceito de rede, que parece ser indispensável para abranger características marcantes dos processos de criação, tais como: simultaneidade de ações, ausência de hierarquia, não linearidade e intenso estabelecimento de nexos. Este conceito reforça a conectividade e a proliferação de conexões, associadas ao desenvolvimento do pensamento em criação e ao modo como os artistas se relacionam com seu entorno. ${ }^{5}$

Seguiremos para apontar os três nós reconhecidos nas produções audiovisuais da empresa Netflix para estabelecer relações com as interpretações propostas sobre como o serviço de streaming pode mudar a forma em que enxergamos a produção audiovisual no mercado de entretenimento, assim como no modo em que identificamos particularidades do processo criativo neste olhar.

\section{o conteúdo televisivo na era digital}

O primeiro nó do qual iremos discutir é sobre a produção de conteúdo presente na plataforma de streaming da Netflix. Ao se tratar sobre conteúdo, percebemos três diferentes elementos que permeiam este nó específico. Para o primeiro, buscamos referências de Domenico De Masi e as teorias do autor sobre grupos criativos, assim como o autor Vincent Colapietro, quando este trata sobre a subjetividade do ser humano.

Para Colapietro, (2016) o que o autor coloca em foco não é o processo de criação, mas sim a origem da criatividade do artista. O que nos é claro, é que a criatividade não é o local de se explorar para decifrar o processo criativo, visto que é algo inerente ao sujeito criador. Muito pelo contrário, percebemos que o "sujeito como comunidade" significa reconhecer que, o sujeito como criador, possui muitos outros elementos que constituem sua imaginação e que acabam auxiliando durante o processo criativo.

Os locais de criatividade, portanto, passam a ser os lugares onde diversas práticas se interceptam ou aqueles onde a mesma prática se volta a si mesma. O local da criatividade não é a imaginação do indivíduo; os locais da criatividade são os caminhos, aparentemente não

\footnotetext{
${ }^{4}$ Musso, Pierre. A filosofia da rede. In: PARENTE, André (Org.). Tramas da rede. Porto Alegre: Sulina, 2004. p.17-38; p. 25.

${ }^{5}$ SALLES, Cecília Almeida. Redes de Criação: Construção da obra de arte. $2^{\text {a }}$ ed., Vinhedo: Editora Horizonte, 2006 , p. 17.
} 
imaginativos, que um participante comprometido toma e por meio dos quais tenta levar adiante algum projeto. ${ }^{6}$

Sendo assim, o indivíduo como criador, se torna um sujeito com muitas práticas e elementos a serem decifrados em seu ato criador. $\mathrm{O}$ ato em si, pode ser identificado ao longo de diversos passos seguidos em seu tempo. O tempo aqui, se torna um auxiliador importante para o processo. Desta forma, podemos falar sobre as teorias de Domenico De $\mathrm{Masi}^{7}$, e suas contribuições para a maneira em que devemos enxergar o pensamento criativo quando o processo se constitui em um coletivo.

Conforme aponta o autor, dentro de uma empresa, mais especificamente, a "capacidade criativa do grupo", depende de um espiral em que ele se molda e define. Desta maneira, o grupo não pode se comprometer a ter apenas um estímulo único de trabalho, mas se concentrar em relações interativas que permitem que cada indivíduo se solidifique em sua vocação natural.

Com isso, podemos definir a equipe criativa como sendo um dos elementos presentes no nó de produção de conteúdo da empresa Netflix. Ao refletir sobre o indivíduo em seu caminho para elaborar um projeto, ainda mais tratando sobre equipes de produção, identificamos a importância de diferentes indivíduos se complementando e enxergando o projeto final como algo coletivo. Desta forma, o processo criativo aqui, se torna um ato comunitário que se estende para além do trabalho individual. Percebemos um olhar para o processo criativo da empresa Netflix, especificamente no seriado "Stranger Things" - lançada em 2016 e criada por Matt Duffer e Ross Duffer. Para tratar sobre a equipe, a forma em que a contratação de um dos atores mirins interferiu na construção do personagem é um exemplo relevante que nos mostra o trabalho colaborativo. Shawn Levy, produtor executivo da série comenta sobre a contratação do ator Gaten Matarazzo e seu personagem "Dustin Henderson":

Para crédito dos Duffer, eles são muito fortes em suas opiniões, mas ajustam a estratégia criativa de acordo com o que é fornecido a eles. Muitos personagens foram reescritos e redefinidos como resultado do que vimos nos atores ... Dustin foi moldado como resultado da escalação de Gaten Matarazzo. ${ }^{8}$

Além disso, conforme aponta Colapietro, ao levar em consideração o encontro do sujeito entre outros indivíduos como parte do processo criativo, no caso de produções audiovisuais no serviço de streaming, devemos levar em consideração a forma em que o próprio público se comporta como parte deste processo. E assim deduzir que o impacto do consumidor deste conteúdo sob o próprio processo em si é de extrema relevância. Ainda mais ao considerar a maneira em que o público se torna cada vez mais participativo no contexto de produções audiovisuais. "Em vez de falar sobre produtores e consumidores de mídia como ocupantes de papéis separados, podemos agora considerá-los como participantes interagindo de acordo com um novo conjunto de regras, que nenhum de nós entende por completo".

${ }^{6}$ Colapietro, Vincent. "Os locais da criatividade: sujeitos fissurados, práticas entrelaçadas". In: PINHEIRO, A. \& SALLES, C.A. (orgs.) Jornalismo expandido: práticas, sujeitos e relatos entrelaçados. São Paulo: Intermeios, 2016, p. 59.

${ }^{7}$ DE MASI, Domenico. Criatividade e grupos criativos: Descoberta e Invenção. vol. 1. Rio de Janeiro: Sextante, 2005 a. p. 159.

${ }^{8}$ MCINTYRE, Gina. Stranger Things: worlds turned upside down. New York: Del Rey/Melcher Media, 2018, p. 36

Tradução nossa.

${ }^{9}$ JENKINS. Op. cit., p. 30. 
Seguimos para falar sobre outro elemento presente na construção de conteúdo que são os roteiros. Para isso, trago novamente um olhar sobre a série "Stranger Things" e a maneira em que a plataforma busca referências para a construção de suas histórias. Principalmente, quando damos destaque para a maneira em que esta série ganhou reconhecimento mundial. Um dos fatores principais que levaram a grande audiência foi o fato de conter diversos elementos que remetessem a referências nostálgicas dos anos 80 e filmes clássicos da época como, por exemplo, ET, Goonies e Alien. Visto isso, muitos críticos se perguntaram sobre a construção narrativa da série e o motivo desses elementos serem inseridos no roteiro. $\mathrm{O}$ especialista em estratégia e criatividade digital, Gustavo Miller, publicou um artigo, em que ele salientava que esta produção pode ter sido "a maior obra de arte do algoritmo da Netflix"10. De acordo com Dan Cohen, executivo da 21 Laps Entertainment, quando ele estava em busca de um novo projeto, a proposta dos irmãos Duffer encaixou no gênero que ele estava procurando:

Eu estava constantemente ouvindo das pessoas esse amor por esse gênero esquecido, e eu sempre estava procurando por algo na veia disso. Quando me deparei com o piloto dos irmãos Duffer, a qualidade era tão alta, os personagens eram tão reais. Não estavam tentando ser nenhuma das coisas que o inspiraram. Foi simplesmente ótimo e parecia que você tinha sido transportado para $1980 .^{11}$

Levantamos este ponto pois percebemos que esta série, com todas as referências identificadas nos episódios, demonstra o grande valor de se incluir elementos reconhecíveis pelo público. Assim, enxergamos o terceiro elemento inserido no nó da rede sobre a produção de conteúdo que classificamos como busca referencial. A necessidade de se inserir diferentes referências, sejam de séries antigas ou objetos de outras épocas, que possuem a finalidade de gerar no público uma sensação nostálgica para estabelecer um vínculo de proximidade e identidade.

É importante aqui comentar que esta busca de referências está diretamente vinculada com a constante análise de algoritmos que a empresa é conhecida por fazer. Conforme já apontado anteriormente sobre o artigo de Gustavo Miller, Stranger Things é uma das principais séries das quais reconhecemos o monitoramento de dados influenciando na criação de conteúdo. Desta forma, seguiremos agora para discorrer sobre o segundo nó da rede da empresa Netflix, o algoritmo monitorado.

\section{A influência do algoritmo na construção do roteiro}

Como empresa, a própria plataforma já afirmou que um dos seus maiores diferenciais é o fato de poder oferecer recomendações de filmes e séries para os seus assinantes. Isso se dá por meio de um monitoramento de dados em que a empresa consegue mapear o que o público está assistindo e, principalmente, o que o público está gostando de assistir. Em entrevista para Tom Vanderbilt da revista Wired no ano de 2013, dois então empresários da Netflix - Carlos Gomez-Uribe, VP de inovação de produto e algoritmos de personalização e Xavier Amatriain, Diretor de engenharia - explicaram como funciona o monitoramento de dados da empresa e a maneira em que isso ajuda a pensar em novas formas de atingir e agradar o público.

\footnotetext{
${ }^{10}$ MILLER, Gustavo. Seria Stranger Things uma obra de arte do algoritmo da Netflix? [on line]. 2016. Disponível em: https://www.linkedin.com/pulse/seria-stranger-things-uma-obra-de-arte-do-algoritmo-da-gustavo-miller/. Acesso em 03 dez. 2017.

${ }^{11}$ MCINTYRE. Op. cit., p. 23 Tradução nossa.
} 
Sabemos o que você assistiu, procurou ou classificou, assim como a hora, data e dispositivo. Nós acompanhamos as interações do usuário, como navegação ou comportamento de rolagem. Todos esses dados são alimentados em vários algoritmos, cada um otimizado para uma finalidade diferente. Em um sentido amplo, a maioria dos nossos algoritmos baseia-se no pressuposto de que padrões de visualização semelhantes representam gostos de usuário semelhantes. Podemos usar o comportamento de usuários semelhantes para inferir suas preferências. $^{12}$

Sendo assim, é de extrema importância identificar o monitoramento de dados como uma característica principal da empresa. Além disso, é compreendermos a maneira em que o monitoramento está diretamente relacionado com a equipe criativa já mencionada anteriormente. O motivo é que, com o olhar sobre os algoritmos, a empresa estabeleceu diferentes condições para a construção dos roteiros das séries originais. De uma certa forma, a produção de novas séries está diretamente vinculada com a forma em que o público reage a produções já existentes.

Da mesma forma em que tratamos sobre a construção de roteiro anteriormente, é importante retomar este ponto para compreender o processo de criação quando tratamos sobre o monitoramento de dados. Uma questão importante que identificamos sobre a criação de uma nova série é a pesquisa relacionada a qual público irá assistir o conteúdo. Por isso, os dados que são analisados diariamente podem fornecer um possível direcionamento para alguns detalhes específicos que o roteiro pode conter, de forma que facilite o sucesso da série.

Sobre o processo criativo, Cecilia Salles (2011) identifica cinco pontos importantes que auxiliam na conceituação do processo criativo. São eles: o "movimento transformador", a "tradução intersemiótica”, o "processo de conhecimento", as "verdades artísticas" e a "experimentação". Destes conceitos, falaremos aqui de três que oferecem relações com o algoritmo monitorado proposto como um nó da rede.

Sobre o "processo de conhecimento", atrelado ao "movimento transformador", reconhecemos a relação com a forma em que a Netflix extrai os seus dados como forma de "recompensa material". A autora explica que, ao longo de todo processo criativo, o artista busca através de suas percepções em conjunto com os recursos utilizados, a melhor forma de seguir com o que está sendo estabelecido como obra. Desta forma, é importante definir o processo criativo sobre o olhar da equipe criativa, pois esta está construindo um olhar singular sobre o mesmo propósito.

A criação como um processo de inferências; já a ação transformadora mostra um modo como um elemento inferido é atado a outro. Pode-se perceber, ao longo do processo criador, dois momentos transformadores especiais: a percepção e a seleção de recursos artísticos. ${ }^{13}$

A autora também explica que o artista busca pesquisar sobre o mundo exterior de forma que elementos podem servir de marca para o que será construído ao longo do processo. Aqui, reconhecemos o conceito de processo de conhecimento como um ponto importante sobre a forma como a Netflix estabelece nexos com os dados que estão sendo monitorados, a fim de propor conteúdos relevantes para o público que está assistindo diariamente outros conteúdos similares. Por assim dizer, para a empresa, o monitoramento e análise dos dados é o contato mais próximo com o mundo exterior.

\footnotetext{
${ }^{12}$ VAnderbilt, Tom. The Science behind the Netflix algorithms that decide what you'll watch next. [on line]. 2013. Disponível em: https://www.wired.com/2013/08/qq_netflix-algorithm/. Acesso em 03 dez. 2017. Tradução da autora.

${ }^{13}$ SALLES, Cecília Almeida. Gesto Inacabado: processo de criação artística. $5^{\text {a }}$ ed., São Paulo: Intermeios, 2011 , p. 95.
} 


\begin{abstract}
O artista, quando sente necessidade, sai em busca de informações. Neste caso, poderia se falar em um modo consciente de obtenção de conhecimento, que está relacionado à pesquisa de toda ordem. Podemos encontrar rastros de coleta de informações, por exemplo, sobre assuntos a serem tratados, sobre técnicas a serem utilizadas ou sobre as propriedades da matéria-prima que está sendo manuseada. ${ }^{14}$
\end{abstract}

Sendo assim, reconhecemos os dados monitorados pela empresa não apenas como um grande elemento na construção de produções audiovisuais, mas principalmente como um elemento importante para o olhar do pesquisador que analisa e rastreia quaisquer documentos do processo criativo. Ao tratar sobre documentos digitais, não temos referências apenas aos dados de propriedade da empresa, mas também quaisquer outros algoritmos que são passíveis de monitoramento por parte do pesquisador.

Novamente, trago a importância de se falar sobre o comportamento do público. Percebemos a forma em que a Netflix identifica a necessidade de agradar o público e oferecer, não apenas produções, mas a própria plataforma como um serviço individualizado pois o mercado compreende o impacto de um consumidor participativo. Como aponta Henry Jenkins, "muitos líderes da indústria afirmam, que a razão principal de a televisão não poder continuar a operar do mesmo modo é porque está perdendo os espectadores mais jovens, que esperam maior influência sobre a mídia que consomem". ${ }^{15}$

Neste sentido, tratamos sobre o público participativo com relação a forma em que os fãs das séries atuam em suas redes sociais. Podemos dizer que o indivíduo que compartilha, comenta e faz postagens de seus gostos e opiniões pessoais de séries recém lançadas, possui um efeito sobre a maneira em que novas produções serão criadas. Isto, por si só, é um elemento importante a ser considerado por pesquisadores do processo criativo.

Com isso, seguimos para falar sobre a "experimentação" tratada por Cecilia Salles. Ela define a experimentação como encontros perceptivos e as testagens que o criador realiza em seu tempo de dedicação com o que se está sendo criado. Desta maneira, o criador está diretamente relacionado ao que ele mesmo desenvolve de iniciativas como forma de compreender mais ainda o objetivo e o caminho que gostaria de seguir. Por este lado, a obra é transformadora pois está aberta a constantes mudanças e alterações na medida em que as tentativas fornecem informações com possíveis traços das respostas mais esperadas pelo artista.

Preferimos falar da experimentação como movimento e não como evolução, não há segurança, por parte do criador, de que a obra em construção esteja caminhando de uma forma pior para outra melhor. A melhora não é uma certeza. Nas idas e vindas do processo, assistimos a muitas recuperações de formas negadas. ${ }^{16}$

A partir daqui, falaremos sobre os conteúdos prontos entregues ao público e o último nó, a reprodução instantânea. Desta maneira, serão feitas relações com o processo criativo, a partir do modo em que o receptor escolhe assistir as séries transmitidas e a forma em que isso pode servir como influência para futuros processos criativos para as plataformas de streaming.

\footnotetext{
14 Ibidem, p. 130.

15 JENKINS. Op. cit., p. 326.

16 SALLES. Ot. cit., p. 153.
} 


\section{Os modelos de reprodução on demand}

O modo como o público consome conteúdo nos dias de hoje é muito relevante para se pensar no modelo de criação das produções do serviço de streaming. $\mathrm{O}$ fato de uma série poder ser reproduzida e assistida tanto na TV quanto na tela do celular ou do computador, é prova de que a maneira em que recebemos e temos o contato sensível com a mensagem já se altera com diferentes possibilidades de interpretação.

O termo on demand - sob demanda - já nos indica um fator importante do serviço de streaming. A possibilidade de acessar o conteúdo em qualquer momento e em qualquer lugar. Além disso, indica também o perfil do sujeito que esteja de fato demandando o conteúdo mais relevante para ele. Sendo assim, quando pensamos sobre público-alvo, sabemos que estamos tratando sobre aquele mesmo indivíduo que está exigindo mais produções para o seu perfil. Isso, por si só, é um fator importante a ser levado em consideração para estudos sobre o processo criativo de produções audiovisuais. Uma característica a ser mencionada com a criação de conteúdos para múltiplas plataformas é o chamado binge watching:

A própria reexposição de um determinado programa no cômodo serviço já ajudava o púbico a crescer, mas então, com a popularização desses serviços, ganhou monta o fenômeno chamado binge watching, ou "assistir compulsivamente", algo como o que nós popularmente conhecemos no Brasil como maratonas, mas em escala maior. ${ }^{17}$

É importante destacar a questão de maratonas quando tratamos sobre os modelos de reprodução destes conteúdos pois percebemos as diferentes maneiras em que o público pode acessar e escolher a forma em que vai assistir aquela história. De uma certa forma, falamos sobre o conteúdo instantâneo pois, as séries lançadas nesta plataforma, são disponibilizadas já com as temporadas completas.

Esse novo, digamos, método de se assistir a um conteúdo pensado de maneira seriada veio inclusive a introduzir interessantes discussões sobre qual seria a forma "correta" de se consumir esse conteúdo - tudo em sequência ou em pausas? - e até uma reavaliação de alguns elementos tradicionais típicos das séries, como o gancho no fim do episódio, que não mais introduz uma semana de ansiedade, e sim alguns meros segundos de suspense até que comece o episódio seguinte. Presume-se que algum impacto também foi sentido pelos roteiristas na forma de elaborar a série como um todo e cada episódio. ${ }^{18}$

O que antes chamávamos o primeiro episódio de uma série como "piloto", pois o primeiro episódio servia como referência para os criadores medirem a possível audiência e determinar se a série deve sofrer alterações no roteiro, agora, em plataformas de streaming, devemos olhar para a primeira temporada inteira como um "piloto". Além disso, não identificamos no serviço de streaming, a necessidade de esperar um longo período de tempo para assistir ao próximo episódio. Nos parece, que o propósito final é este. Afinal de contas, a própria plataforma automaticamente já inicia o próximo episódio, a não ser que o indivíduo escolha pausar a transmissão.

Isto, sem dúvida, afeta o modo em que os roteiristas pensam em como adaptar o roteiro para estas condições. Os criadores de séries on demand preferem o público assista à temporada de uma só vez. Ted Sarandos, Diretor Executivo de Conteúdo da Netflix explica o porquê da importância de desenvolver uma temporada sem "interrupções" de tempo.

\footnotetext{
${ }^{17}$ SEABRA, Rodrigo. Renascença: a série de TV no século XXI. Belo Horizonte: Autêntica Editora, 2016, p. 276.

${ }^{18}$ Ibidem, p. 277.
} 
[...] antes de começarmos a fazer nossos shows originais com o House of Cards, todos os shows que tivemos na Netflix foram escritos para serem assistidos um episódio por semana, [...] mas eles foram criados para iludir o público a voltar toda semana e eles também tiveram que recontar ao público o que aconteceu na semana passada, porque $40 \%$ da audiência não viu o episódio da semana, então você passava muito tempo escrevendo o roteiro, precisando lembrar o público sobre o que aconteceu, o que é meio bobo quando você assiste na Netflix três ou quatro episódios de uma vez. House of Cards foi na verdade o primeiro show provavelmente na história da televisão a ser escrito para ser visto de uma só vez, então foi escrito sem intervalos para comerciais, sem cliffhangers, foi escrito sem exposição, e tudo isso soma para uma hora de televisão. Provavelmente são mais 20 minutos de narração, o que permite mais profundidade de personagem, mais complexidade, tudo o que você pode fazer quando sabe que não está perdendo o público ou que parte do público não viu na semana anterior, e eu acho que foi uma das mudanças mais fundamentais para o ato da televisão provavelmente desde o aparecimento da televisão premium ou da televisão sem comerciais. ${ }^{19}$

Aqui, portanto, destacamos a forma como o modelo de reprodução pode afetar o processo criativo. Mais uma vez, abordamos questões sobre a "experimentação" apontadas por Salles (2011). A autora explica a maneira em que os artistas, para obterem uma rica investigação sobre a arte tratada, criam hipóteses sobre como a obra poderá ser criada, de forma em que estas hipóteses se tornam testes de experimentação.

No momento da construção da obra, hipóteses de naturezas diversas são levantadas e vão sendo postas à prova. São feitas seleções e opções que geram alterações e que, por sua vez, concretizam-se em novas formas. As testagens que geram novas formas são responsáveis pelo movimento criador. Tudo é mutável, mas nem sempre é mudado. ${ }^{20}$

A partir disso, percebemos a experimentação com um ato, em relação a empresa Netflix, de explorar os testes de hipóteses provindos de um monitoramento de dados e que se resulta em uma reprodução de um conteúdo completo que seja disponível a todos. Este acesso permite para que em retorno, a empresa possa compreender também qual é o lugar em que o público possui mais fácil acesso, assim como qual é o conteúdo que ele decide assistir nas condições encontradas. Segundo Ted Sarandos:

Nós temos acesso ao que as pessoas assistem e como a visualização acontece de forma agregada. Mas nós realmente não usamos dados para influenciar as decisões criativas. Isso ainda é muito uma forma de arte, de usar as intuições das pessoas para decidir quais shows vamos fazer. Não há dados que digam "melhor contratar este ator em vez daquele" ou "faça esse tipo de produção" é tudo baseado primeiramente no show. O que os dados ajudam, e reflete sobre esse desafio que mencionei anteriormente, é relativo ao custo, se eu consigo fazer esta produção, então tendo um bom controle do que você acha que o público pode ser, é útil usar dados para coisas desse tipo, mas não para escolhas criativas. ${ }^{21}$

\footnotetext{
${ }^{19}$ SARANDOS, Ted. Nos bastidores com a Netflix: uma conversa com Ted Sarandos, Diretor Executivo de Conteúdo. São Paulo, FAAP, 2019 (Comunicação oral). Tradução da autora.

${ }^{20}$ SALLES. Op. cit., p. 144.

${ }^{21}$ SARANDOS, Ted. Nos bastidores com a Netflix: uma conversa com Ted Sarandos, Diretor Executivo de Conteúdo. São Paulo, FAAP, 2019 (Comunicação oral). Tradução da autora.
} 
Conforme aponta o executivo, por mais que os dados estudados pela empresa podem não afetar criativamente no roteiro, eles apontam para se uma série deve ser produzida ou não, se terá público ou não. São informações que devemos considerar como formas de experimentação nestes processos. "Desse modo, as modificações são, nesses casos, resultados da discrepância entre aquilo que se tem e aquilo que se quer: o construído e a necessidade. Esta diferença gera testagens, de toda ordem, em que novas possibilidades de obra são postas à prova.. ${ }^{22}$

Por assim dizer, poderíamos estabelecer diferentes questionamentos ao falar sobre a maneira em que cada série é construída em relação temporal. Stranger Things, já mencionada, é uma série que segue uma história de forma linear, diferente da série Black Mirror. Lançada em 2011, esta série possui um formato diferente de conteúdo. A primeira temporada possui apenas três episódios que podem ser assistidos em qualquer ordem de visualização. Este formato se segue ao longo de todas as temporadas até a $5^{a}$ que é a mais recente lançada em junho de 2019. Cada episódio possui em média, 1 hora e 20 minutos de duração, o que acaba causando uma sensação de que você não está assistindo um mero episódio de série de televisão, mas sim um longa metragem.

Como consequência da testagem deste formato, a Netflix lançou em 2018 Black Mirror: Bandersnatch, um conteúdo que se vendeu como interativo para o público que é fã da série. Neste filme, o indivíduo podia escolher o final da história a partir de uma série de perguntas sobre o que o protagonista deveria seguir. Precisamos reconhecer que este tipo de formato não é novo. Reconhecemos estas técnicas já no conteúdo televisivo a muitos anos. Desta forma, identificamos em produções como esta, assim como em Stranger Things, uma tendência pela busca de técnicas e referências já conhecidas pelo público o que nos força a refletir sobre o que devemos reconhecer como experimentação nestas produções.

Sobre a experimentação e os modelos de reprodução, Salles também identifica os diferentes métodos do criador. Um deles, a autora classifica como um constante confronto entre o limite e possibilidade: "limites internos ou externos à obra oferecem resistência à liberdade do artista. O artista é incitado a vencer os limites estabelecidos por ele mesmo ou por fatores externos, como data de entrega, orçamento ou delimitação de espaço” ${ }^{23}$. Com isso, percebemos relações com a forma em que identificamos estes limites impostos sobre a criação de produções audiovisuais.

A própria "experimentação" como conceituação do processo demonstra um aspecto importante para o método do grupo criativo que seria a constante tomada de decisão. Estas decisões refletem também esta tensão entre a liberdade e o limite. Compreendemos a importância de se pensar e refletir sobre o processo criativo de séries do serviço de streaming a fim de se explorar o modo como estes conteúdos serão afetados e influenciarão futuras produções.

\section{Considerações Finais}

Para este trabalho, partimos para abordar os três nós identificados no processo criativo de produções audiovisuais voltadas para o serviço de streaming, especificamente da empresa Netflix. Foram eles, a produção de conteúdo, o algoritmo monitorado e a reprodução Instantânea. Ao tratar sobre a produção de conteúdo, identificamos três aspectos importantes que afetam esta rede. Identificamos que a equipe criativa é importante para estabelecer nexos para a criação completa de uma produção audiovisual. Em relação a isso, reconhecemos a importância da equipe para a construção dos roteiros. Com isso, inseridos dentro do próprio conteúdo,

\footnotetext{
22 SALLES. Op. cit., p. 154.

${ }^{23}$ SALLES, Cecília Almeida. Gesto Inacabado: processo de criação artística. $5^{\text {a }}$ ed., São Paulo: Intermeios, 2011 , p. 69.
} 
detectamos elementos reconhecidos como referências de outras produções. Esta busca referencial foi importante para falar sobre o algoritmo monitorado.

Sobre o monitoramento de dados, em relação próprio processo de criação, identificamos a importância da pesquisa por tendências e um olhar sobre o público-alvo que, sem dúvida, impactam não apenas no meio escolhido para a transmissão do conteúdo, mas também em quais técnicas serão escolhidas para se construir a produção como um todo. Destacamos aqui questões conceituais de Cecilia Salles sobre o processo de criação que foram o "movimento transformador", o "processo de conhecimento" e a "experimentação".

Entendemos que a análise de dados faz parte do processo para os criadores compreenderem de forma mais clara, qual será o público que eles irão atender. Isto é o conhecimento do ambiente exterior à obra, explicado pela autora. Além disso, a equipe criativa como um todo está em constante chance de mudanças na medida em que cada sujeito da equipe também pode sofrer transformações. Aqui, reconhecemos o "movimento transformador" da obra em processo, o que nos levou para tratar sobre a "experimentação" de modo que entendemos que os dados representam testagens e assim o processo segue em um caminho de acasos e, consequentemente, transformações que, nem sempre devem ser consideradas como pioneiras, mas como uma mera interpretação da vontade do público.

Por último, foram ressaltadas características do processo criativo com os aspectos reconhecidos sobre a "reprodução instantânea". Compreendemos que a maneira em que o público consome este conteúdo, seja o suporte escolhido, quanto em qual momento e lugar, está diretamente relacionado com a maneira em que o próprio processo é afetado, principalmente na construção de roteiro. Novamente identificamos características sobre a "experimentação".

Conforme apontado por Ted Sarandos, os dados são importantes para melhor compreender o que o público espera do conteúdo. São informações que auxiliam em decisões importantes a serem tomadas como, por exemplo, o custo de produção de uma série. Informações como estas representam as hipóteses e testagens no processo criativo destas produções. Além disso, são estes dados que permitem uma liberdade ou limitação na criação de uma série para o serviço de streaming.

Com certeza compreendemos o impacto gigantesco que a audiência pode ter na construção de um roteiro. Este impacto que sempre esteve presente, desde programações televisivas até as adaptações de roteiro após o lançamento de um episódio "piloto", agora, mais do que nunca, se estende para a além do processo criativo de produções audiovisuais.

As diferenças de conteúdo nas séries destacadas foram importantes para entender como a produção audiovisual na era digital está se transformando. No entanto, esta transformação parece partir do público e não do criador em si. Se identificamos experimentações, são impostas pelo que o indivíduo quer assistir e não pela qualidade da história sendo contada. Sendo assim, séries de televisão em serviços de streaming, continuam a ser séries de televisão. Desta maneira, questionamos se estas experimentações devem ser vistas como inovações no mercado de entretenimento, ou se devemos compreender que a era digital ainda pode ser altamente explorada no contexto de produção e no serviço on demand.

\section{Referênias}

Colapietro, Vincent. "Os locais da criatividade: sujeitos fissurados, práticas entrelaçadas". In: PINHEIRO, A. \& SALLES, C.A. (orgs.) Jornalismo expandido: práticas, sujeitos e relatos entrelaçados. São Paulo: Intermeios, 2016.

DE MASI, Domenico. Criatividade e grupos criativos: Descoberta e Invenção. vol. 1. Rio de Janeiro: 
Sextante, 2005 a.

Criatividade e grupos criativos: Fantasia e concretude. vol. 2. Rio de janeiro: Sextante, 2005 b.

JENKINS, Henry. Cultura da convergência. Tradução de Susana L. de Alexandria. 2a ed., São Paulo: Aleph, 2009.

MCINTYRE, Gina. Stranger Things: worlds turned upside down. New York: Del Rey/Melcher Media, 2018.

Miller, Gustavo. Seria Stranger Things uma obra de arte do algoritmo da Netflix? [on line]. 2016.

Disponível em: https://www.linkedin.com/pulse/seria-stranger-things-uma-obra-de-arte-do-algoritmo-dagustavo-miller/. Acesso em: 03 dez. 2017.

Musso, Pierre. “A filosofia da rede”. In: PARENTE, André (Org.). Tramas da rede. Porto Alegre: Sulina, 2004. p.17-38.

SALLES, Cecília Almeida. Redes de Criação: Construção da obra de arte. $2^{\mathrm{a}}$ ed., Vinhedo: Editora Horizonte, 2006.

Gesto Inacabado: processo de criação artística. $5^{\mathrm{a}}$ ed., São Paulo: Intermeios, 2011.

SEABRA, Rodrigo. Renascença: a série de TV no século XXI. Belo Horizonte: Autêntica Editora, 2016.

SARANDOS, Ted. Nos bastidores com a Netflix: uma conversa com Ted Sarandos, Diretor Executivo de Conteúdo. São Paulo, FAAP, 2019 (Comunicação oral).

VANDERBILT, Tom. The Science behind the Netflix algorithms that decide what you'll watch next. [on line]. 2013. Disponível em: https://www.wired.com/2013/08/qq_netflix-algorithm/. Acesso em: 03 dez. 2017. 